\title{
FROM KNOWING TO DOING:
}

\section{REFLEXIVITY, LEADERSHIP AND PUBLIC RELATIONS}

\subsection{Introduction}

In an article about leadership in this journal more than 30 years ago, Thayer (1986) appropriated a Spanish proverb to make the point that discussing or reading about leadership is not the same as doing it. The proverb he uses warns theatrically that to talk of bulls is not the same as being in the bullring. Four decades on from Thayer's evocation of the bullring we still know little in public relations (PR) about the experiences practitioners have of leading others and, more specifically, the challenges associated with enacting desired leadership behaviours in the work place. This oversight is not surprising for while there has been a recent upsurge in research, leadership in PR remains an under-developed area of inquiry despite its importance to the impact, development and reputation of the profession (Berger, 2013; Meng, 2014; McKie \& Willis, 2015; Petersone \& Erzikova, 2016). This article's interest in the personal experiences of practitioners seeking to enact desired leadership behaviours, in addition to contributing to a nascent area of public relations scholarship, further advances knowledge by connecting PR to relevant research from outside of the field.

The study considers how exploring the interplay between a leader and their context enhances understanding of the conditions under which knowledge is enacted, or rather not enacted, in a specific leadership context. In doing so, the discussion introduces perspectives from organization and leadership studies which highlight the importance of reflexivity to 
leadership learning (Cunliffe, 2002; Cunliffe \& Easterby-Smith, 2004). In the article reflexivity is characterised as the capacity to critically scrutinize assumptions, interests and interpretative bias through the consideration of "contested and contrary positions" (Dovey et al., 2017, p. 24). This reflexive focus and the requirement to excavate personal experience for the purpose of learning, supports the insight that variability in leadership performance can be linked to "underlying influences which are not immediately recognised by individuals through their lived experience" (Kempster, 2006, p. 4). In addition to intersecting with scholarship from outside of the discipline, the article's interest in reflexivity supports calls from within PR for a greater reflexive orientation in research and the profession to enhance our understanding of power, culture, practice and paradox (Falkheimer \& Heide, 2016). Although other public relations researchers have engaged with reflexivity in a variety of ways, such as to capture the essence of good functional practice (Vercic et al., 2001), as a means of enhancing critical thinking (L'Etang, 2008) and discussed its virtues as a methodological tool (Macnamara, 2012; Waymer, 2012), this study represents the first time a reflexive lens has been applied systematically to leadership practice in PR.

In support of this reflexive endeavour the study further addresses an absence of empirical work that focuses on the situated experiences of PR leaders. Through the discussion of an exploratory research project the article considers the reflexive potential of a programme of research interviews with PR leaders and provides examples to illustrate the role this type of qualitative research can play in leadership studies. In particular, the interviews demonstrate how reflexivity can help researchers and practitioners engage with the contextual challenges of the work place. The wider implications of the study for PR research, practice and pedagogy are also highlighted. By using the learning generated by the empirical 
research to highlight the dangers of neglecting the context in which leadership is practised, the article essentially engages in a process of problematization (Alvesson \& Sandberg, 2011) designed to challenge the uncritical promotion of normative and decontextualised approaches to PR leadership.

\subsection{Reflexivity and connecting with context}

The study's contextual focus is influenced by two complementary strands of research in contemporary leadership studies. The first concerns the need to consider the relationship between a leader's ability to exercise agency and their requirement to confront the constraints which surround them. Nohria and Khurana (2010) argue that navigating the tension between agency and constraint is at the heart of leadership practice and promote its importance to future scholarship. The second strand of research seeks a better understanding for how scholars and practitioners might address the disconnection between principle and action, framed by Pfeffer and Sutton (2000) as the "knowing-doing gap" (p. x). They argue that the divide between knowing and doing is "one of the most important and vexing barriers to organizational performance" (p. $x$ ) and is a phenomenon which is especially pronounced in the leadership field. As Swart (2011) notes "knowledge is only valuable when it is enacted" and highlights the need to be "mindful of the importance of the inter-relationship between knowledge and its context" (p. 320, italics in original). Bringing these two research themes together serves to highlight that an essential form of 'knowing' for PR leaders includes a heightened appreciation of the environmental conditions which impact on their agency as practitioners. 
Considering these challenges meets a need in PR for alternative perspectives on leadership which enable the field to widen its gaze, in an attempt to offset the rational and prescriptive ideals predominating in existing research (Fransden \& Johansen, 2010; Falkheimer \& Heide, 2016). The article's contextual orientation is designed particularly to help practitioners consider their position in relation to social and organisational power relations through a reflexive process which explores their individually felt experiences and actions (Cunliffe, 2002; 2004). This focus is important given that with some notable exceptions (Berger, 2005; Berger \& Reber, 2006) research in the field with an interest in PR leaders and leadership has tended to ignore the existence and influence of power. Through its orientation the study therefore serves to encourage a shift to more contextually intelligent ways of viewing leadership which recognises the complex relationship PR practitioners have with their working environment.

To inform such an investigation, Sutherland (2012) reinforces how reflexivity has become the focus of leadership development suggesting it creates a "transformational bridge between experience and learning" (p. 27). Highlighting its importance to professional development, Iszatt-White and colleagues (2017) suggest that reflexivity is "as fundamental to the learning that can be gleaned from surfacing our own implicit knowing, as it is to the emancipatory agenda surrounding issues of power" (p. 583). In making their case, these researchers then draw on Wittgenstein's (1953) foundational insight that what occurs in reflexivity is not the 'outside-in' reflective learning associated with theoretical insights or intellectual epiphany, but moments in which we "understand something that is already in plain view" (p. 89). Given this capacity to reconfigure the taken-for-granted from being 
something that is used for thinking to "that which we think about" (Hibbert, 2013, p. 805), reflexivity possesses the capability to disrupt by clearing out existing knowledge through "the questioning of assumptions and perceptions to make room for new insights" (IszattWhite et al., 2017, p. 584). In the context of this study reflexivity therefore provides an opportunity to explore the subjective and interactional elements of organizational life (Sutherland, 2012) which impact on the contemporary realities of leading in public relations.

\subsection{Exploring the lived experiences of PR leaders}

The specific leadership context investigated in this study's empirical research concerns the work place experiences of PR leaders seeking to empower the people in their teams. Empowerment is defined as the formal, informal and oblique processes and actions which encourage a sense of personal efficacy, self-determination and value amongst an individual or group working on a task (Conger \& Kanungo, 1988; Thomas \& Velthouse, 1990; Chia, 2011;). When considering empowerment the study looks specifically at the role of PR practitioners as team leaders, supporting the insight that the ability to work with others in the PR function is an important leadership attribute (Berger \& Meng, 2014). The emphasis on team leadership is also important given the PR literature tends to consider leadership in the context of practitioners' core strategic role, or in terms of their relationships with people outside of the PR team.

The concept of empowerment provides further fertile ground for the inquiry given it is the type of idea which has the potential to impregnate organizations and professional groups about what constitutes good and effective leadership practice (Alvesson \& Sveningsson, 
2003; Maynard et al, 2014). Employee empowerment has even been likened to a movement in the contemporary workplace (Seibert et al., 2004). However, the purpose of the study is not to make the case for or against empowerment as a viable leadership practice. By exploring the ambition of a group of PR practitioners to be 'empowering leaders', it is designed instead to highlight the danger of disregarding the wider context of leadership (Schyns et al., 2012) and through its reflexive lens to expose situational conflicts and challenges (Cunliffe, 2002). Considering the tensions and contradictions within a particular context is a productive way of improving understanding about a subject (Siltaoja et al., 2015) and is especially pertinent given leadership is recognised as a concept which is replete with paradox (Bolden et al., 2016).

To better understand the paradoxes that make the practice of leadership so difficult empowerment is a good place to start given it is an aspect of leadership that is itself characterised by an inherent conflict. This conflict relates to the seemingly contradictory idea that in an empowerment context leaders increase their power and effectiveness by giving power away. This perspective supports Berger's (2005) understanding of empowerment as a form of power with relations in which "dialogue, inclusion, negotiation and shared power guide decision making" (p. 6). In his study of senior corporate PR executives, Berger contrasts this democratic framing of power with power over relations which relate to "a traditional dominance model where decision making is characterized by control, instrumentalism and self-interest" (p. 6). He then notes how this latter conceptualization of power links to notions of hegemony, positioned by Roper (2005) as a form of "domination without physical coercion through the widespread acceptance of particular ideologies and consent to the practices associated with those ideologies" (p. 70). 
However, rather than aligning with a form of suppression through which people acquiesce to structures, power relations and value systems which do not serve their interests, an adherence to empowerment instead commits PR leaders to dialogue, collaboration, joint decision making and the sharing of power.

The study therefore explores an influential and contradictory leadership idea (in this case, the requirement and desire to be 'empowering') and considers the role reflexivity can play in helping us to better understand the situational conditions which impact on PR leaders' experiences in this context. This emphasis returns us to the study's concern with leaders' ability to exercise agency by confronting the constraints which surround them (Nohria \& Khurana, 2010) and overcoming the "knowing-doing gap" (Pfeffer \& Sutton, 2000, p. x). Exploring these issues is timely for the field and provides the opportunity to consider the wider challenges of leadership practice through the consideration of associated research, pedagogical and professional implications.

\subsection{The study's research design}

Given its focus the study is designed to explore the organizational conditions under which PR leaders enact strategies associated with empowering the members of their team. This interest leads to three questions which are also investigated: what specific factors shape leadership practice in this context; how do these factors operate in this context; and what issues do these factors generate for PR leaders? To inform the research process semistructured interviews with fifteen PR leaders were conducted on the telephone by the author, recorded and then transcribed to gather primary source data. Only senior public 
relations executives with board level experience in the private or public sector were selected for interview. The PR leaders who took part in the study (five women and ten men) are all British and work in the United Kingdom. They comprise of two chief executive officers each responsible for running an international public relations consultancy, a director with a global remit working in a large public relations network and seven in-house PR directors (two from the private sector and five from the public sector). In addition, the sample includes three PR agency owner managers (all of whom previously held senior roles as inhouse PR directors) and two self-employed consultants, one who has led a number of large public sector communication directorates and the other their own PR agency. The corporate in-house PR directors work for companies in the FTSE 100 while their public sector counterparts head up the communication function for various central government departments and other large public sector bodies.

This sampling strategy of engaging in what Bowen (2008) calls "elite" interviews (p. 278) was adopted for three reasons. First, in order to begin to develop a leadership perspective from practice it was helpful to talk with PR professionals recognised by their colleagues as having a formal leadership role (all participants are, or have been, members of an organization's board of directors). Second, to discuss these issues with people who have extensive leadership experience (each of the participants has led PR teams for at least 10 years). Third, it was felt they could offer insights into the operational as well as the policy and/or strategic decision-making behind specific leadership practices (Pang \& Yeo, 2012). This attribute has the potential to inform a discussion around the contextual conditions that might be shaping their empowerment practice as leaders. 
A key objective of the interviews is to stimulate a practical form of reflexivity amongst the research participants, focussing in particular on the conditions under which a desire to be empowering was either enacted, or not enacted. To better investigate the conditions influencing the PR leaders' behaviour the study's method builds on Archer's (2003) idea of conversational collaboration in reflexive interviews, during which participants are not only encouraged to reflect upon themselves in relation to their circumstances but to also consider the influence of other properties and powers. Smith and Elger (2014) note how Archer in her promotion of reflexive interviewing "emphasises the autonomy of human agents, with interior thoughts that belong to them alone" while simultaneously highlighting the importance of getting people to reflect upon themselves "in relationship to others" ( $p$. 123).

To support this approach different interview questions were used to encourage a form of reflexive engagement between the author and the research participants. In line with Archer's (2003) guidance, these questions were designed to assist with the exploration of the participants' reflexivity regarding their subjective experience, as well as their relationship with the surrounding social situation. Informing the specific types of questions used in the interviews, the study draws on the advice provided by Danermark and colleagues (2002) by implementing a blended approach enabling different forms of extreme cases to be compared. From a leadership and empowerment perspective, the selection of this strategy was further informed by the work of Kouzes and Posner (2012) who ask questions of research participants linked to their 'personal best' leadership experiences. 
Kouzes and Posner have used these experiences, and the behaviours and actions associated with them, to inform their work around how leaders mobilize others and empower them to act. In the author's interviews the participants were asked to think about the times when they were at their best as a leader and to consider the conditions which allowed this to happen. They were then asked to think about the opposite extreme, that is, the times when they were at their worst and to reflect on the particular conditions impacting on this context. According to Danermark et al. (1997) the consideration of such extreme cases (that is, the 'best' and 'worst' experiences) provides an opportunity to learn about the conditions for the normal area under investigation by generating data where key factors might appear more clearly than in other situations. Given the character of these interviews ethical safeguards were implemented to ensure the interviewees' anonymity is respected (for example, all of their names have been changed in this article) and that other sensitive information remains confidential. A semi-structured interview guide was also applied to ensure a consistent approach.

\subsection{Emerging conflicts and contradictions}

Having outlined relevant aspects of the study's design, the article now moves on to highlight a number of key insights generated during the empirical research before considering the data's wider implications. This discussion is designed to illustrate the reflexive potential of the interviews, as well as the broader benefits such an orientation has for the field, particularly its capacity to enhance understanding of the social contexts, constraints and resources within which PR leaders act (Smith \& Elger, 2014). According to Alvesson and Skoldberg (2009) this aspiration in reflexive research involves searching for data which has 
"a more profound meaning than that immediately given or conventionally understood" ( $p$. 284). They go on to emphasise that in this research context "the work of interpretation is (more) central" while "the empirical material - texts in various forms - is the subject of attempts to assess meanings and develop revealing insights" (p. 284).

Working initially with the PR leaders' own experiences and interpretation of their context, the most revealing insights generated by the interviews concern the tensions that are said to exist between the espoused practices and values of the research participants and what are framed as the wider demands of the organization. A set of conflicts and contradictions are discussed which the PR leaders attribute to the existence of particular power relations within their own organizations. Most of the PR leaders interviewed in the study claim to be advocates of empowerment and suggest that empowering others is a key priority. The potential exists, of course, for this type of discourse to be positioned as a form of leaderspeak, a concept introduced in the study to frame the unreflective use of organizational and/or professional jargon which leaders take for granted and use uncritically. For example, James' comment in his interview about empowering people "for the wrong reasons" in order for him (and other senior colleagues) to cope with an expanding workload suggests a superficial and instrumental understanding of empowerment. However, what also emerges from the interviews is that for some participants their claims to be empowering stretch beyond an uncritical promotion of organizational and professional discourses to connect instead with their own identity and sense of self. Robert, for example, talks about being passionate about empowerment and how "it was in my DNA" while Scott, in answer to the question of whether empowering others comes easily to him, notes that "it does come easy to me...I think it's a personality 
thing". He goes on to say, "I am the kind of person who works better by...allowing the team to get on with it", adding that, "I personally thrive more in that team environment and I am personally quite uncomfortable being prescriptive with people". From the language they use (phrases such as "it was in my DNA", "it's a personality thing" and "I personally thrive") Robert and Scott seem to regard this way of working as an intrinsic part of their personal identity and who they are as leaders.

Having been told by Robert and Scott their propensity to be empowering leaders is driven by core aspects of their personality and even biological make-up, the reflexive exploration of their extreme cases ('best' and 'worse' leadership experiences) leads to an unravelling of these definitive and passionate claims. A common and recurring theme emerges which is how particular organizational needs override other considerations, such as their desire to empower others. Having spoken confidently earlier about his natural propensity to empower, Robert emphasises later that he is guided ultimately by what the organization requires of him financially and how this impacts negatively on what he does as a team leader. He speaks of his approach to leading a group of colleagues at a time when he was being asked by the organization "to start cutting costs" and "save money". He talks about his leadership approach during that period and far from being empowering notes, "I was managing them with a rod of iron, and a lot of them were wriggling". He then elaborates by saying that managing them correctly in the previous months meant:

“They were so uncomfortable. I think deep down they knew they couldn't do the job in the way it needed to be done, that three of them left, and that might sound a bit 
brutal but that was a different sort of leadership really, that was doing what the organization needed."

For Robert the requirement for a different type of leadership with "brutal" consequences is justified by a wider organizational agenda associated with saving money. This context compels him to work in a particular way as a leader and results in a situation in which managing his team "correctly" is about making them feel "uncomfortable". In Scott's interview similar themes emerge around the idea of particular leadership approaches being both encouraged and discouraged by an organization's economic requirements. He also emphasises the importance of protecting the company's income and the influence this factor has on what he does as a leader. This point is illustrated when he describes how his leadership practice was swayed by the demands of a client, causing him to behave in a way that ran counter to his values:

“I just thought commercially I can't say no to this and every part of me knows it's the wrong thing....and I know they [the team] are looking at me and thinking you [expletive], you talk about values and you talk about leadership...I basically made a decision based purely on commercialism and money rather than on what was the right thing to do."

This example provides another illustration of how economic considerations take precedence over what the research participants perceive as doing "the right thing" as a leader. Although 
Scott argues his propensity to empower is driven by an aspect of his personality, the episode he describes shows how his natural enthusiasm for certain leadership practices like empowerment is curtailed ultimately by considerations associated with maximising the organization's financial assets. A distinction, as well as a tension, is therefore created between doing what is right as a leader and doing what is right for the organization.

\subsection{Disempowering narratives and cultures}

Through its identification of particular economic influences the study begins to inform about the conditions under which hegemony might operate, particularly its materiality and the conditions of its emergence. For example, by considering Robert and Scott's version of events the study simultaneously pays attention to their preferences (empowerment) and constraints (economic considerations), therefore highlighting the potential interplay between their individual preferences as a leader and power. In this context the economic considerations can be positioned as a form of hegemony leading to Robert's revelations about his "brutal" practices and Scott's sense of being a charlatan in the eyes of his team. Rather than engaging in the power with relations associated with empowerment, both leaders slide into power over mode by adopting behaviours associated with control and instrumentalism.

While the claims made for this economic influence on their behaviour might be positioned as a convenient form of self-justification by both Robert and Scott, the potential also exists 
for it to have an impact beyond their individual construction of these events. This analysis of their context is supported by other leadership research in the academy. For example, discussing hostile organizational environments where 'brutal' forms of leadership are legitimised Raelin (2003) observes that "tough decisions" are executed by leaders regardless of the harm they might do to employees as "accomplishing the mission of the enterprise must come first" (p. 10). More specifically, Starkey and Hall (2012) draw attention to the prevalence of an economic narrative of management and how it can distort leadership practice. They note how this narrative, by focussing almost exclusively on financial performance, sets a cultural frame which "privileges a relatively narrow view of how leaders should think and act" (p. 82). In the context of leadership behaviour the economic narrative of management is positioned as a structural and hegemonic discourse which works against other voices in the organization, such as those highlighting the need for empowerment. In these environments one set of priorities prevails over others which results in the promotion of regressive leadership behaviours. This discourse therefore has the potential to generate a self-perpetuating cycle within organizations which, in the context under review in this study, promotes disabling over enabling leadership practice and disempowerment over empowerment.

These types of narrative can therefore set the frame for a cultural context with the potential to distort the behaviour of leaders. In his interview, Andrew discusses the disconnections he confronts between the claims organizations make about their culture and his lived experience as an employee. He says that with regard to practices like empowerment "the worst of all worlds is when you try to operate in an organization that pretends it is one 
thing, but actually its behaviours, its incentives, the way it punishes, all points to the other direction". Highlighting these conflicts links with the concerns of other PR researchers who explore the relationship between organizational culture and leadership. Meng (2014) noting the "dearth of empirical research linking public relations leadership and organizational culture" (p. 364) concludes there is "a direct, positive influence from organizational culture in the achievement of excellent leadership in public relations" (p. 378). This study complements Meng's appreciative conclusion about the importance of culture, albeit by shining a light on cultural influences with the potential to impact negatively on leadership behaviour.

\subsection{Implications for theory and practice}

The experiences described by the research participants highlight how regressive leadership practice can be associated with doing what the organization requires and/or what is financially necessary. In the illustrations discussed in the interviews economic demands are blamed for underpinning practices the PR leaders claim they dislike and which run counter to their stated beliefs about leadership. Even if the veracity of the interviewees' version of events and their commitment to particular leadership approaches are challenged, the study's findings still lead to the wider question of the extent to which prescribed and desired leadership behaviours are actually implemented and sustained in practice? Applying a reflexive lens highlights the dangers of the field relying on normative and decontextualized approaches to leadership. Indeed, the research suggests that applying a critical eye on the 
claims made by leaders (and the case made for leadership more generally) is relevant even for those PR practitioners who appear to identify strongly with and passionately promote a preferred leadership approach.

If promoted and idealised leadership behaviours do not consistently reflect what goes on in PR practice, the next question to consider is what role do they play? For example, are terms like empowerment no more than 'buzzwords' in the wider canon of leaderspeak? Alternatively, building on Robert and Scott's passionate identification with the term, do such ideas instead represent a way in which PR practitioners try to make sense of themselves as leaders and the world of work in which they operate? As Alvesson and Sveningsson (2003) note the ideas about leadership circulating around both academia and practice can be interpreted as "esteem-enhancing identity work for those vulnerable to - or attracted by the modern leadership discourse" (p. 983). They go on to note this discourse may impact more on a leader's efforts to define who they are - or would like to be - in ideologically appealing ways, rather than reflect what they actually do.

The analysis of the interviews also points to the importance of recognising the complexity of the PR leaders' operating context. For example, the structural economic factors highlighted in the study point to a need to better understand the interplay between the different facets of a PR leader's role. While research in our field may set out particular parameters for what being a good PR leader should entail, little regard is given to the impact of the other areas of their work, whether functional, administrative or managerial. Those of us who engage with 
PR leaders as researchers and educators will often hear them discussing the aspects of their role that 'get in the way' of doing what they believe to be right. In future leadership research attention therefore needs to be given to how the other aspects of being a PR practitioner might enhance or hinder desired leadership practices. In short, our field needs to recognise the impact less personally alluring aspects of PR work have on leadership. With a wide range of departmental, organizational and functional responsibilities - compounded by the influence of different resource issues - more needs to be discovered about how in these contexts practitioners successfully go about being the leader they want to be.

When exploring these issues the PR field should also prepare itself for the realisation that leadership might be present to only a very limited extent in certain settings, necessitating a recognition that it is a more elusive, ambiguous and messier phenomenon than portrayed previously in our literature. Understanding leadership as a fluid rather than a fixed construct additionally highlights the importance of exploring the perceived failures, as well as successes, of PR leaders. Furthermore, this type of research may reveal, as this study suggests, that where leadership does occur it can be more instrumental, ruthless and directive than contemporary ideas about being a good leader suggest.

\subsection{From methodology to pedagogy}

A final set of points to make about the implications of this study concerns its design and method. A difference between this project's empirical aspects and existing research into PR 
leadership is its reflexive orientation. This way of approaching the study has provided an opportunity to critically consider and then problematize the discourse of PR leaders. The discussion of particular research findings' has led to one understanding for why leadership might be practised in ways that contradict with espoused approaches and desires. The study therefore highlights the reflexive potential of PR leaders' discourses and uncovers examples of how encouraging a practical form of reflexivity between researcher and research participant can surface insights of wider importance. These findings highlight the need for the field to embrace a diverse range of methodologies and methods in its quest to better understand and promote good leadership practice.

It is suggested that this type of research, as well as highlighting the utility of a reflexive turn in the field's leadership research, provides opportunities to improve directly the practice of leadership in public relations. A reflexive orientation to the professional challenges of leadership should be encouraged amongst leaders to help offset the normative and essentialist tendencies predominating in existing research, as well as the rhetoric of leadership promoted in contemporary organizations, both of which have an impact on how leadership identities are constructed. By highlighting the importance of reflexivity to not only PR research but also practice, the article begins to illustrate its potential for pedagogy, particularly as a way of encouraging reflexivity amongst practitioners. In doing so, the article illustrates the benefits of our field engaging with the growing body of work concerned with reflexive pedagogy (Hibbert, 2013; Hibbert \& Cunliffe, 2015; Iszatt-White et al., 2017) and intersects specifically with a call for those engaged in professional leadership development to devise new strategies for "reflexive engagement" (Smolovic Jones et al., 2015, p. 405). In 
these educational environments reflexivity is one method which can help PR leaders work on their effectiveness through a process of self-confrontation (Beck, 1996). The growing promotion of reflexive approaches further highlights the important and on-going role they have in enhancing workplace learning (Matsuo, 2013).

Taken together, these insights make a case for the development of new reflexive strategies in PR given how organizational demands have the potential to make it difficult for leaders to follow either the rhetoric of modern leadership and/or their preferred approaches. Socalled good or desired practice can be difficult to realise and instead situations arise in which PR professionals seem to exercise leadership in ways they claim to disapprove of. A reflexive orientation can therefore help scholars, educators and professionals become more aware of the complexity inherent in PR contexts, particularly the power relations which envelope and distort practice. Whereas reflection is positioned as a systematic thought process concerned with simplifying experience, reflexivity results in "complexifying thinking or experience by exposing contradictions, doubts, dilemmas and possibilities" (Cunliffe, 2002 , p. 38). The interviews with the PR leaders help to highlight its potential as a method to investigate the factors which can inhibit desired leadership behaviours through its capacity to make power and hegemony more visible, while laying bare the fiction of leadership. As the episodes highlighted in the research show, it has the potential to generate a more nuanced view of the interaction between agency and structure by exploring the ebb and flow between 'doing' and 'being done to' (Nicholson \& Carroll, 2013). This attribute is especially important as an enhanced appreciation for how power manifests itself can lead to a better understanding of leadership and will help the PR field to rise to a challenge it has yet to address adequately. 


\subsection{The study's limitations}

Although this article recognises the potential of reflexivity it is important to acknowledge that it is not positioned as a cure for all of the ills of leadership practice in the PR field. Rather, it should be regarded as just one approach which can help us to consider, and where appropriate address, the challenges of the leadership 'bullring'. This study also makes no claims to be representative. It draws on data generated by interviews with a small sample of practitioners and focusses on a few selected episodes recounted by the research participants. While these interviews yield insights of use to theory, practice and pedagogy further studies are required to more fully consider the potential of reflexivity for leadership studies in public relations. With an increased data set, greater focus could also be given to similarities and differences between different types of context whether organizational, sectoral, or in terms of the enactment of different leadership practices. Additional studies would also provide an opportunity to consider the impact of issues such a gender, race and culture.

Another limitation is associated with this type of reflexive research, that is, its capacity to search for tendencies rather than the existence of concrete conditions. For example, the phenomenon described are best understood as being highly contextual and emergent, instead of in terms of universal and predictable patterns. Reflexivity therefore helps to illuminate the factors shaping the behaviour of leaders, rather than identifying constant event regularities or connections (Hesketh \& Brown, 2004). Such elusive properties mean 
that researchers must instead be content with capturing fleeting glimpses of particular factors at work, insights which can then be used to inform further theory building and practice.

While the accounts of individual leaders are an essential starting point for this type of social investigation, it is also recognised that leadership is a relational process and the potential exists for a richer research picture to be generated by working with the accounts of others (such as team members) and/or observing the leaders in action. Comparing leaders' own interpretation of events with additional types of data has the potential to yield new insights about the contextual complexity inherent in leadership. It is also important to note that leadership is distributed throughout organizations, systems and communities rather than restricted to an elite cadre of people operating at the top of a hierarchy and associated with a particular job title (Gronn, 2000). This study works with senior professionals for a range of valid reasons but future studies should also consider the leadership experiences of a wider range of PR practitioners to gain a more nuanced picture of contemporary leadership practice.

\subsection{Summary}

This article highlights the importance of connecting PR leadership research with issues around context. Disregarding the wider context of leadership can result in the promotion of a 'one-best-way' of leading, rather than recognising that PR leaders have different starting 
points and operate in different contexts (Schyns et al., 2013). Encouraging reflexive approaches in research, pedagogy and practice is highlighted as one way in which the PR field can initiate a process of contextual engagement. Through the discussion of its empirical findings the study suggests two priorities. First, a greater reflexive focus in PR research on the conditions affecting leadership behaviour and the consequences these have for practitioners. This understanding can then be used to support the second priority which is to foster a form of contextual intelligence amongst PR practitioners which can help them to better appreciate the culture, structures and processes in the organization which specifically impact on how they do their job. Drawing on this understanding, PR leaders can then consider the behaviours and strategies they should enact in order to get things done.

While public relations theory and practice champions the importance of contextual intelligence to the discipline's functional effectiveness in terms of understanding the wider stakeholder environment and its impact on an organization, community or system, the fine grain of organizational life and its influence on those seeking to lead has been overlooked. This focus is important because as the interviews conducted for this study illustrate while PR leaders can articulate what they should or would like to be doing, issues arise when they seek to enact espoused practices and behaviours in the work place. Investigating this challenge also provides an opportunity for PR scholars to engage productively with practitioners through research and pedagogical activities.

By focussing on the challenges confronting practitioners seeking to enact espoused leadership behaviours this article tackles a subject which requires greater attention in the PR field. Leadership is an experiential activity and its complexity resides in its sustained 
execution rather than the challenge of conceptual understanding. The article sets out how exploring the challenge of empowering people provides one example through which to better understand the 'bullring' in which leadership is performed and practised in public relations. The study's finding around how economic considerations can shape leadership behaviour adds further value by pointing to the need for a critical orientation which focuses on the power related aspects of leadership and the potential for domination in organizations. The research highlights how particular narratives can create hostile organizational environments where 'brutal' forms of leadership are legitimised by practitioners. The potentially pervasive influence of such narratives therefore serves as a general warning against wishful and superficial calls for PR practitioners to enact particular leadership practices.

\section{References}

Alvesson, M., \& Sandberg, J. (2011). Generating research questions through problematization. Academy of Management Review, 36(2): 247-271.

Alvesson M., \& Skoldberg K. (2009). Reflexive methodology: New vistas for qualitative research. London: SAGE. 
Alvesson M., \& Sveningsson S. (2003). Good visions, bad micro-management and ugly ambiguity: Contradictions of (non-)leadership in a knowledge-intensive organization. Organization Studies, 29(6): 961-988.

Archer M. (2003). Structure, agency and the internal conversation. Cambridge: Cambridge University Press.

Beck, U. (1996). Risk society and the provident state. In S. Lash, B. Szerszynski \& B. Wynne (Eds.), Risk, environment and modernity: Towards a new ecology(pp. 27-43). London: Sage.

Berger, B. K. (2005). Power over, power with, and power to relations: Critical reflections on public relations, the dominant coalition, and activism. Journal of Public Relations Research, 17(1): 5-28.

Berger, B. K. (2013). Leadership and public relations. In R. L. Heath (Ed.), Encyclopedia of public relations(pp. 508-509). Thousand Oaks, CA: Sage.

Berger, B. K., \& Meng, J. (Eds.). (2014). Public relations leaders as sense makers: A global study of leadership in public relations and communication management. New York, NY: Routledge. 
Berger, B. K., \& Reber, B. (2006). Gaining influence in public relations: The role of resistance in practice. Mahwah, NJ: Lawrence Erlbaum.

Bolden, R., Witzel, M., \& Linacre, N. (2016). Leadership paradoxes: Rethinking leadership for an uncertain world. London: Routledge.

Bowen, S. (2008). A state of neglect: Public relations as "corporate conscience" or ethics counsel. Journal of Public Relations Research, 20: 271-296.

Chia, R. (2011). Complex thinking: Towards an oblique strategy for dealing with the complex. In P. Allen, S. Maguire \& B. McKelvey (Eds.), The SAGE handbook of complexity and management(pp. 182-198). London: Sage.

Conger, J. A., \& Kanungo, R. N. (1988). The empowerment process. Integrating theory and practice. Academy of Management Review, 13(3): 471-482.

Cunliffe A. (2002). Reflexive dialogical practice in management learning. Management Learning, 33(1): 35-61. 
Cunliffe A. (2004). On becoming a critically reflexive practitioner. Journal of Management Education, 28(4): 407-426.

Cunliffe A., \& Easterby-Smith M. (2004). From reflection to practical reflexivity: Experiential learning as lived experience. In: M. Reynolds \& R. Vince (Eds.), Organising Reflection(pp.3046). Aldershot: Ashgate.

Danermark B., Ekstrom M., Jakobsen L., \& Karlsson J. C. (1997) (Eds.). Explaining society: Critical realism in the social sciences. Abingdon, Oxon: Routledge.

Danermark B., Ekstrom M., Jakobsen L., \& Karlsson J. C. (2002) (Eds.). Explaining society: Critical realism in the social sciences. London: Routledge.

Dovey K., Burdon S., \& Simpson R. (2017). Creative leadership as a collective achievement: An Australian case. Management Learning, 48(1): 23-38.

Falkheimer, J., \& Heide, M. (2016). A reflexive perspective on public relations: On leaving traditional thinking and uncovering the taken-for-granted. In J. L'Etang, D. McKie, N. Snow \& J. Xifra (Eds.), The Routledge handbook of critical public relations(pp. 162-172). Abingdon, Oxon: Routledge. 
Fransden, F., \& Johansen, W. (2010). Strategy, management, leadership and public relations. In R. L. Heath (Ed.), The SAGE handbook of public relations(pp. 293-306). Thousand Oaks, CA: Sage.

Gronn, P. (2000). Distributed properties: A new architecture for leadership. Educational Management Administration and Leadership, 28: 317-338.

Hesketh, A., \& Brown, P. (2004). I say tomato, you say tamato: Putting critical realism to work in the knowledge worker recruitment process. In S. Fleetwood \& S. Ackroyd (Eds.), Critical realist applications in organisation and management studies(pp. 309-326). London: Routledge.

Hibbert P. (2013). Approaching reflexivity through reflection. Issues for critical management education. Journal of Management Education, 37(6): 803-827.

Hibbert P., \& Cunliffe A. (2015). Responsible management. Engaging moral reflexive practice through threshold concepts. Journal of Business Ethics, 127(1): 177-188.

Iszatt-White M., Kempster S., \& Carroll B. (2017). An educators' perspective on reflexive pedagogy: Identity undoing and issues of power. Management Learning, 48(5): 582-596.

Kempster S. (2006). Leadership learning through lived experience. Journal of Management and Organization, 12: 4-22. 
Kouzes, J. M., \& Posner, B. Z. (2012). The leadership challenge: How to get extraordinary things done in organizations. San Francisco, CA: Jossey-Bass.

L'Etang, J. (2006). Public relations: Concepts, practice and critique. London: Sage.

Macnamara, J. (2012). The global shadow of functionalism and excellence theory: An analysis of Australasian PR. Public Relations Inquiry, 1(3): 367-402.

Matsuo M. (2013). Leadership of learning and reflective practice: An exploratory study of nursing managers. Management Learning, 43(5): 609-623.

Maynard M. T., Gilson L. L., \& Matthieu J. E. (2014). Empowerment - fad or fab? A multilevel review of the past two decades of research. Journal of Management, 38(4): 1231-1281.

McKie, D., \& Willis, P. (2015). Advancing tendencies? PR leadership, general leadership, and leadership pedagogy. Public Relations Review, 41(5): 628-635.

Meng, J. (2014). Unpacking the relationship between organizational culture and excellent leadership in public relations: An empirical investigation. Journal of Communication Management, 18(4): 363-385.

Nicholson H., \& Carroll B. (2013). Identity undoing and power relations in leadership development. Human Relations, 66(9): 1225-1248. 
Nohria, N., \& Khurana, R. (2010). Advancing leadership theory and practice. In N. Nohria \& R. Khurana (Eds.), Handbook of leadership theory and practice: An HBS centennial colloquium on advancing leadership(pp. 3-26). Boston, MA: Harvard Business Press.

Pang, A., \& Yeo, S. L. (2012). Examining the expertise, experience, and expedience of crisis consultants in Singapore. Public Relations Review, 38(5): 853-864.

Petersone, B., \& Erzikova, E. (2016). Leadership and public relations in two emerging markets: A comparative study of communication management in Latvia and Russia. Public Relations Review, 42: 192-200.

Pfeffer, J., \& Sutton, R. (2000). The knowing-doing gap: How smart companies turn knowledge into action. Boston, MA: Harvard Business School Press.

Raelin, J. A. (2003). Creating leaderful organizations: How to bring out leadership in everyone. San Francisco, CA: Berrett-Koehler.

Roper, J. (2005). Symmetrical communication: Excellent public relations or a strategy for hegemony? Journal of Public Relations Research, 17(1): 69-86.

Schyns B., Tymon A., Kiefer T., \& Kerschreiter, R. (2013). New ways to leadership development: A picture paints a thousand words. Management Learning, 44(1): 11-24. 
Seibert S. E., Silver S. R., \& Randolph W. A. (2004). Taking empowerment to the next level: A multiple-level model of empowerment, performance and satisfaction. Academy of Management Journal, 47(3): 332-349.

Siltaoja M., Malin V., \& Pyykkonen, M. (2015). We are all responsible now: Governmentality and responsibilized subjects in corporate social responsibility. Management Learning, 46(4): 444-460.

Smith C., \& Elger T. (2014). Critical realism and interviewing subjects. In: P. K. Edwards, J. O' Mahoney \& S. Vincent (Eds.), Studying organizations using critical realism: A practical guide(pp.109-131). Oxford: Oxford University Press.

Smolovic Jones O., Grint K., \& Cammock P. (2015). Public leadership development facilitation and the crossroads blues. Management Learning, 46(4) 391-411.

Starkey, K., \& Hall, C. (2012). The spirit of leadership: New directions in leadership education. In S. Snook, N. Nohria \& R. Khurana (Eds.), The handbook of teaching leadership: Knowing, doing and being(pp. 81-98). London: Sage.

Sutherland I. (2012). Arts-based methods in leadership development: Affording aesthetic workspaces, reflexivity and memories with momentum. Management Learning, 44(1): 2543. 
Swart J. (2011). That's why it matters: How knowing creates value. Management Learning, 42(3): 319-322.

Thayer, L. (1986). Rethinking leadership for public relations. Public Relations Review, 12: 312.

Thomas, K. W., \& Velthouse, B. A. (1990). Cognitive elements of empowerment: An "interpretive" model of intrinsic task motivation. Academy of Management Review, 15: 666681.

Vercic, D., van Ruler, B., Butschi, G., \& Flodin, B. (2001). On the definition of public relations: A European view. Public Relations Review, 27(4): 373-387.

Waymer, D. (2012). Each one, reach one: An autobiographic account of a Black PR professor's mentor-mentee relationships with Black graduate students. Public Relations Inquiry, 1(3): 403-419.

Wittgenstein, L. (1953). Philosophical investigations. Oxford: Blackwell. 